\title{
MORPHOMETRY OF OCCIPITAL CONDYLES: IMPLICATIONS FOR TRANSCONDYLAR APPROACH TO CRANIOVERTEBRAL JUNCTION LESIONS
}

\author{
Isaac Cheruiyot, Phillip Mwachaka, Hassan Saidi \\ Correspondence to Isaac Cheruiyot, Department of Human Anatomy, University of Nairobi \\ P.O Box 30197-00100 Nairobi, Kenya. isaacbmn@outlook.com.
}

\begin{abstract}
Partial occipital condylectomies are commonly done in trans-condylar approach to craniovertebral junction lesions. Following such procedures, post-operative atlanto-occipital joint instability and hypoglossal nerve palsies have been reported and has been attributed to population-specific variations in the occipital condyle (OC) dimensions. Determination of these dimensions may aid in minimizing these complications. One hundred and four (104) OC from 52 skulls (27 males, 25 females) were obtained from the osteology department, National Museums of Kenya. Occipital condyle length (OCL), width $(\mathrm{OCW})$, height $(\mathrm{OCH})$, anterior (AID) and posterior (PID) intercondylar distances and the distance from posterior tip of $\mathrm{OC}$ to hypoglossal canal $(\mathrm{HC})$ were obtained using a pair of digital Vernier calipers. The data obtained were entered into SPSS for analysis. The mean OCL, OCW and OCH were 20.59 $\pm 2.05 \mathrm{~mm}$, $12.23 \pm 1.28 \mathrm{~mm}$ and $8.65 \pm 1.08 \mathrm{~mm}$ respectively while AID and PID were $19.66 \pm 2.70 \mathrm{~mm}$ and $38.52 \pm 3.09 \mathrm{~mm}$ respectively. Moderate OC type was the most predominant (60.6\%). Males and females had predominantly moderate and short OC type respectively $(p=0.001)$. The HC was located $9.62 \pm 1.62$ $\mathrm{mm}$ from the posterior tip of the OC. Males had significantly larger OCL $(p<0.001), \mathrm{OCH}(p=0.001)$, PID $(p=0.002)$ and posterior tip of OC to HC distance $(p=0.008)$. Our study population generally has smaller $\mathrm{OC}$ dimensions compared to other populations. Females had significantly smaller $\mathrm{OCL}, \mathrm{OCH}, \mathrm{OC}-\mathrm{HC}$ distance and PID. Clinicians should therefore take this information into consideration during preoperative planning in craniovertebral junction surgeries among Kenyans and particularly in females.
\end{abstract}

Key Words: Occipital condyles, Morphometry, Transcondylar approach

\section{INTRODUCTION}

The occipital condyle (OC) is a bony structure lying anterolateral to the foramen magnum and connects the cranium to the vertebral column (Sinnatamby, 2006). It articulates with the superior articular facets on the lateral masses of atlas, forming the atlanto-occipital joint. The stability of this joint is important and is maintained by congruency of the articular surfaces together with capsulo-ligamentous factors. Deep to each condyle traverses the hypoglossal canal ( $\mathrm{HC}$ ) which transmits the hypoglossal nerve (HGN) and a meningeal branch of ascending pharyngeal artery
(Sinnatamby, 2006; Standring, 2008).

Morphometry of the $\mathrm{OC}$ is important in craniovertebral surgeries, particularly in accessing lesions ventral to the brainstem or at the cervicomedullary junction such HGN schwannomas, foramen magnum meningiomas and cervicomedullary hemangioblastomas (Tange et al., 2001; Suhardja et al., 2003). Transcondylar approach (TA), which involves partial condylectomy by drilling the posterior aspect of the $\mathrm{OC}$ is increasingly being used to access these lesions because it increases the 
surgical field of view and minimize nerve tissue retraction (Pereira et al.,2012; Sahoo et al.,2015). Occipital condylectomies may however complicate with hypoglossal nerve injuries or atlanto-occipital joint instabilities (Banerji, 1999; Sen et al., 2010; Lynch et al., 2013). This has been attributed to variations in the dimensions of the $\mathrm{OC}$ as well as the position of the $\mathrm{HC}$ relative to the posterior tip of OC (Naderi et al., 2005) which may lead to severing of HGN due perforation of the posterior cortex of the $\mathrm{HC}$ (Pereira et al.,2012). Knowledge of morphometry of the $\mathrm{OC}$ and as well as the position of the HC may therefore be useful in decisions regarding extent and direction of condylar drilling to avoid occipito-cervical destabilization and inadvertent injury of the $\mathrm{HC}$ neurovascular structures (Mahajan, 2013). We therefore sought to determine the dimensions of the $\mathrm{OC}$ in a select Kenyan population.

\section{MATERIALS AND METHODS}

This was a descriptive cross-sectional study. One hundred and four occipital condyles from 52 skulls (27 males, 25 females) were obtained from the osteology department of the National Museums of Kenya (NMK). Only adult skulls with permanent dentition and which could be correctly identified for sex were included. Skulls that were broken at the cranial base and those that exhibited obvious deformations were excluded. The occipital condyle (OC) were identified at the base of the skull, extra cranially. Using a pair of digital sliding calipers (Sealey Professional Tools ${ }^{\mathrm{TM}}$ ) accurate to $0.01 \mathrm{~mm}$ [Figure $1 \mathrm{~B}$ ], the following measurements were taken: occipital condyle length, width, height, anterior and posterior intercondylar distances as well as distance from the posterior tip of OC to the $\mathrm{HC}$ [Figure $1 \mathrm{~A}$ ]. Based on length, the $\mathrm{OC}$ was classified into 3 types: type 1 (short: <20mm), type 2 (moderate: $23 \pm 3 \mathrm{~mm}$ ) and type 3 (long :> 26mm) (Naderi et al., 2005).

The collected data were entered into SPSS (version 21.0 Chicago, Illinois) for analysis. Continuous data are reported in means and standard deviations while categorical data are expressed as percentages. Univariable analyses of continuous data were performed using Paired sample t-test to compare average dimensions of the right and left occipital condyles and Student's t-test to compare the average occipital condyle dimensions between male and female subjects. Chi-square test was used to assess gender differences in the proportions of occipital condyle types. A p-value $<0.05$ was considered significant at $95 \%$ confidence interval. Data were represented using tables.

Figure $1 \mathrm{~A} \& \mathrm{~B}$ : Occipital condyle dimensions and the digital caliper used to take the dimensions

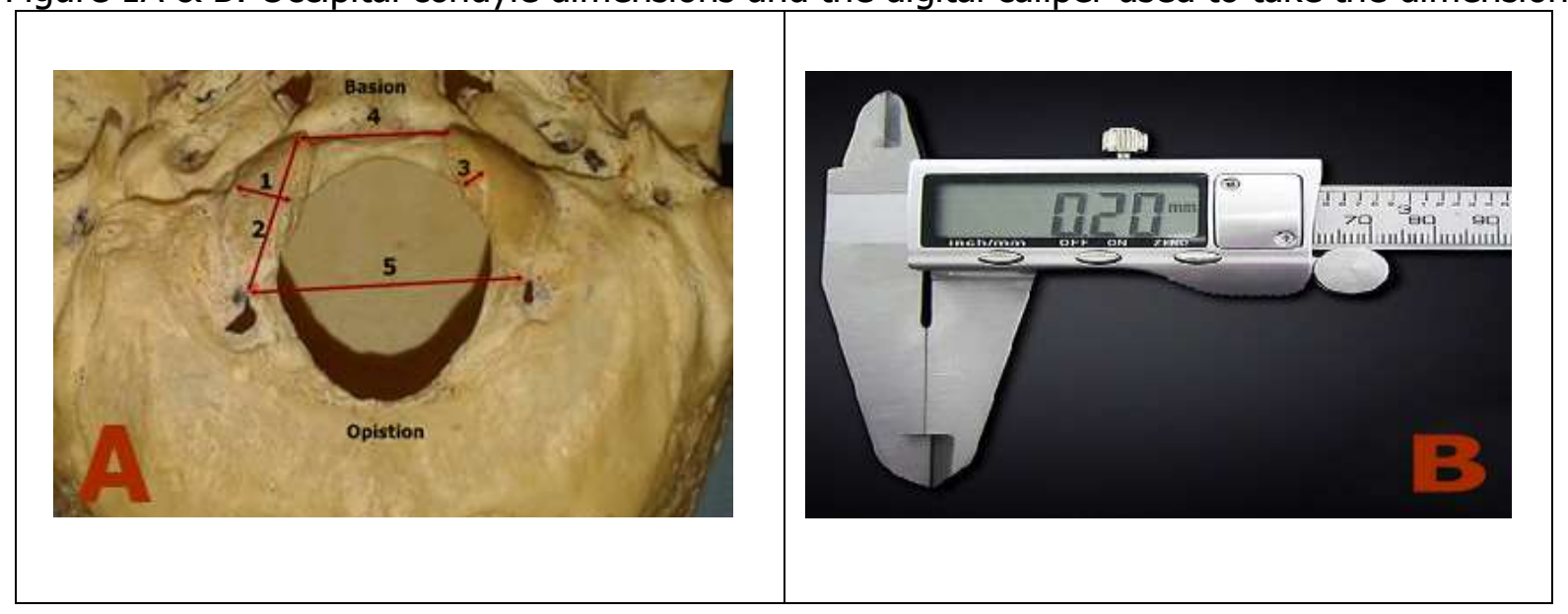

Figure 1: A: Dimensions of the OC: 1- width 2- length 3- height 4-anterior intercondylar length 5-posterior intercondylar length. $\mathrm{B}$ : Vernier caliper used to take measurements of the occipital condyles. 


\section{RESULTS}

i

) Types of occipital condyles based on length Moderate occipital condyle types were the most predominant in this study (60.6\%). Females had a larger proportion of short occipital condyle types compared to males (32.6\%). There was a significant gender difference in the proportions of OC types $(p<0.001)$ [Table 1$]$.

\section{ii) Dimensions of the occipital condyles}

The average occipital condyle length, width and height were $20.59 \mathrm{~mm}, 12.23 \mathrm{~mm}$ and $8.65 \mathrm{~mm}$ respectively while anterior and posterior intercondylar distances were $19.66 \mathrm{~mm}$ and
$38.52 \mathrm{~mm}$ respectively. Females had significantly smaller occipital condyle length $(p<0.001)$, height $(p=0.001)$ and posterior intercondylar distances $(p=0.002)$. No significant side differences were noted in the above dimensions [Table 2].

iii) Position of the hypoglossal canal

The hypoglossal canal $(\mathrm{HC})$ was located at an average distance of $9.62 \mathrm{~mm}$ (Range $=6.39$ 16.92) from the posterior tip of the OC. This distance was significantly greater in males than females $(p=0.008)$ [Table 2].

Table 1: Distribution of occipital condyle types

\begin{tabular}{|l|l|l|l|l|}
\hline OC Type & Male (\%) & Female (\%) & Total (\%) & $\begin{array}{l}\text { Chi-square } \\
\text { Statistics }\end{array}$ \\
\hline $\begin{array}{l}\text { Type } 1(\text { Short) } \\
(<20 \mathrm{~mm})\end{array}$ & $5.8(\mathrm{n}=6)$ & $32.6(\mathrm{n}=34)$ & $38.4(\mathrm{n}=40)$ & \\
\hline $\begin{array}{l}\text { Type } 2(\text { Moderate) } \\
(23 \pm 3 \mathrm{~mm})\end{array}$ & $45.2(\mathrm{n}=47)$ & $15.4(\mathrm{n}=16)$ & $60.6(\mathrm{n}=63)$ & $p<0.001$ \\
\hline $\begin{array}{l}\text { Type } 3(\text { Long) } \\
(>26 \mathrm{~mm})\end{array}$ & $1(\mathrm{n}=1)$ & $0(\mathrm{n}=0)$ & $1(\mathrm{n}=1)$ & \\
\hline
\end{tabular}

Table 2: Side and gender differences in the occipital condyle dimensions

\begin{tabular}{|l|l|l|l|l|l|l|l|}
\hline $\begin{array}{l}\text { Dimension } \\
(\mathrm{mm})\end{array}$ & $\begin{array}{l}\text { Right } \\
\text { condyle }\end{array}$ & Left condyle & P value & Male & Female & P value & Combined \\
\hline Length & $20.51 \pm 2.02$ & $20.59 \pm 2.09$ & 0.958 & $21.64 \pm 1.86$ & $19.46 \pm 1.59$ & $<0.001^{*}$ & $20.59 \pm 2.05$ \\
\hline Width & $12.27 \pm 1.25$ & $12.20 \pm 1.33$ & 0.637 & $12.25 \pm 1.13$ & $12.21 \pm 1.44$ & 0.882 & $12.23 \pm 1.28$ \\
\hline Height & $8.64 \pm 1.10$ & $8.66 \pm 1.07$ & 0.637 & $8.99 \pm 1.15$ & $8.28 \pm 0.87$ & $0.001^{*}$ & $8.65 \pm 1.08$ \\
\hline AID & - & - & - & $19.71 \pm 2.47$ & $19.62 \pm 2.96$ & 0.864 & $19.66 \pm 2.70$ \\
\hline PID & - & - & - & $39.41 \pm 2.73$ & $37.56 \pm 3.21$ & $0.002^{*}$ & $38.52 \pm 3.09$ \\
\hline $\begin{array}{l}\text { Posterior tip } \\
\text { of OC to HC }\end{array}$ & $9.96 \pm 1.70$ & $9.68 \pm 1.55$ & 0.425 & $10.02 \pm 1.94$ & $9.18 \pm 1.03$ & $0.008^{*}$ & $9.62 \pm 1.62$ \\
\hline
\end{tabular}




\section{DISCUSSION}

Moderate type OC $(23 \pm 3 \mathrm{~mm})$ were the most prevalent in our population $(60.6 \%)$. This is agreement with previous studies (Naderi et al., 2005; Natis et al., 2013; Sahoo et al., 2015). However, when compared to other populations, our study population had the highest percentage of short type OC. Further, the OCL obtained in the present study is similar to that obtained among the American population (Wen et al., 1997). This dimension was however shorter than those obtained among the Nigerian (Bello et al., 2013), Turks (Naderi et al., 2005), Indians (Muthukumar et al., 2005), Egyptians (Fetouh and Awadalla, 2009), Brazilians (Pereira et al., 2012), Greeks (Natsis et al., 2013) and Omanis (Kumar and Nagar, 2015).

The differences in the OC length as well as OC types between Kenyans and these populations could be due to differences in the sex composition of the sample populations. Although some authors did not indicate sex composition of their sample populations (Naderi et al., 2005; Fetouh and Awadalla, 2009), those that did had males making up a larger percentage of the sample population. Pereira et al (2012) for instance had a sample of 88 males and 23 females while Bello et al (2013) indicated a male: ratio of 3: 1 in the sample population. It is however known that males have longer $\mathrm{OCL}$ compared to females (Pereira et al., 2012; Bello et al., 2013). It is then plausible that this male predominance within the sample populations may account for the longer OCL obtained in these studies. Differences in OC Length and types between Kenyans and Caucasians (Indians, Turks, Omanis, Greeks and Egyptians) could also be attributed to differences in the genetic composition. Variation in the morphology of cranium has been shown to be influenced by the genetic composition of a person (Smith, 2011). Two quantitative trait loci (QTL) influencing basicranial development in humans have been identified. Loci 12q 13.11 located on chromosome 12 has been linked to the measure of total basicranial length and while loci 2q24.3 located on chromosome number 2 has been linked to measure of anterior basicranial length.
Variations in single nucleotide polymorphisms (SNPs) within these loci has been shown to contribute to $43 \%$ and $46 \%$ of phenotypic variations in basicranial length (Sherwood et al., 2011). Since the occipital bone forms part of the basicranium, it may be possible that these genes also influence OC dimensions. It is then plausible to postulate that variations in single nucleotide polymorphisms (SNP) in these loci among various populations, accounting for variations in OCL. Interestingly, our study populations had shorter OCL compared to other African populations (Nigerian and Egyptians). This could be attributed to variations in cranial sizes between the populations. Nigerians for instance have larger cranial indices compared to Kenyans (Akinbami, 2014). We postulate that this may cause OC remodeling due differential loading at the atlanto-occipital joint. The differences in $\mathrm{OCL}$ between Kenyans and Egyptians (Caucasians) could be due to variations in the SNPs of loci linked to basicranial length.

Females had significantly smaller OCL compared to males $(p<0.001)$. This is in agreement with previous studies among the Brazilian (Oliviera et al., 2013) and the Turkish populations (Gökce et al., 2014). Further, females had significantly larger proportion of short type OC compared to males $(p=0.001)$. Expression of sexual dimorphism within the skeletal system has been attributed to hormonal differences between the sexes that drive bone growth and development at different rates (Callewaert et al., 2010). Androgens cause higher periosteal bone formation and subsequently bone dimensions compared to estrogens (Vanderschueren et al., 2004).

The role of OC length in occipito-cervical stability has been demonstrated in various biomechanical studies. Removal of same amount of bone stock results in greater occipito-cervical instability in shorter condyles compared to longer ones (Vishteh et al., 1998; Naderi et al., 2005). This is due to reduction of articular surface area, resulting in hypermobility (Vishteh et al., 1999, 1998b). This hypermobility is normally 
associated with altanto-occpital joint instability (Caird et al., 2006) and can be fatal when accompanied by neurologic complications. Since our study population generally have shorter OC length with females having much shorter condyles, it is conceivable that these groups may be more vulnerable to atlanto-occipital joint instability. This should therefore be considered during procedures involving occipital condylectomies among Kenyans.

The average width of OC (OCW) obtained in this study was $12.23 \pm 1.28 \mathrm{~mm}$. This was larger than that obtained by among the Turkish population (Naderi et al., 2005). This dimension was however smaller than that obtained among the Indians (Muthukumar et al., 2005), Egyptians (Fetouh and Awadalla, 2009), Nigerians (Bello et al., 2013), Brazilians (Pereira et al., 2012) and Omani population (Kumar and Nagar, 2015). Population variation in OCW could be attributed to genetic differences. Although QTL for OCW has not been identified yet, we postulate that there could be due variations of SNPs in the genomic loci coding for OCW. Population variations in OCW could also be contributed by use of skulls of different ages. Bello et al, (2013) demonstrated an increase in OCW with age. It could therefore be possible that use of skulls of different ages may account for population differences in OCW. Absence of gender differences in OCW suggests that remodeling of OC due to differential loading could be influenced by the types of movements that occur at the atlanto-occipital joint. Since flexion and extension are the predominant movements at this joint, remodeling along the anteriorposterior axis may be favored more than that along Medio-lateral axis. Knowledge of population variations in OCW could be important in occipital condylectomies in procedures such as TA. Wider OC would necessitate a more extensive bony resection compared to narrow ones. Since OCW contributes to the total articular surface at the atlanto-occipital joint, it is conceivable that atlanto-occipital joint instability would be more likely to occur in patients with narrower OC.
The mean $\mathrm{OCH}$ obtained in this study was found to be $8.65 \pm 1.08 \mathrm{~mm}$. this is agreement with a study by Kuman and Nagar (2015) among the Omani population. It was however smaller compared to that obtained among the Egyptian (Fetouh and Awadalla, 2009) and Turkish (Naderi et al., 2005) populations. Human height is a continuous variable and as such is influenced multiple genes. Numerous phenotypic variations in height has been linked to SNP polymorphism at these gene (Lettre et al., 2008). For instance, loci 6q16.1-q1 has been linked to total face and cranial height. Variations in this loci have been shown to account for up to $56 \%$ of phenotypic variations in these dimensions (Sherwood et al., 2011). Although gene loci for OCH has not been identified yet, it is possible SNPs variations in these loci may explain population variations in $\mathrm{OCH}$. Females had a significantly smaller $\mathrm{OCH}$ compared to males ( $p$-value $<0.001)$. There is however paucity of literature describing gender differences in the $\mathrm{OCH}$ for which we could compare. Nonetheless, the gender difference in $\mathrm{OCH}$ could be attributed hormonal differences. Testosterone hormones is known to cause formation of larger bone volume compared to estrogens (Vanderschueren et al., 2004). This difference could also be due to differences in genetic encoding by the $Y$ and $X$ chromosomes which influences bone deposition and subsequently bone mass (Zanotti et al., 2014). Taking into account smaller OCL and OCW, smaller $\mathrm{OCH}$ means that our sample population has less $\mathrm{OC}$ bone volume. They would therefore require smaller amount of bony resection compared to other populations with larger OC dimensions.

The current study found that the mean AID was $19.66 \pm 2.70 \mathrm{~mm}$ while PID was $38.52 \pm 3.09 \mathrm{~mm}$. These dimensions were larger those obtained by among the Iranian population (Bayat et al., 2014). They were however smaller than those obtained among the Turkish (Naderi et al., 2005; Ozer et al., 2011), Indian (Lobo et al., 2015) and Egyptian (Fetouh and Awadalla, 2009). The population difference in intercondylar 
dimensions could be due to varying angulations of the OC relative to the sagittal plane. Larger sagittal intercondylar angles are associated with larger intercondylar distances as the OC are further apart. This difference could also be attributed to the varying prevalence of $\mathrm{OC}$ overriding into the foramen magnum. This is where OC protrudes into foramen magnum due to its medial displacement. Mahajan, (2013) reported amount overriding ranging from 0 - 10.1 $\mathrm{mm}$. although we did not take into account overriding $\mathrm{OC}$ in the present study, it may be possible that different populations have different amounts of OC overriding, therefore varying intercondylar distances.

Females had significantly smaller PID compared to males $(p=0.002)$. This is agreement with a study among the Turkish population by (Gökce et al., 2014). This suggests that females have narrow sagittal intercondylar angles compared to males. We postulate that smaller intercondylar distances among females could be attributed to larger amounts of overriding $\mathrm{OC}$ into the foramen magnum compared to males.

Presence of wider intercondylar distances has been shown to be advantageous in accessing ventral cranio-vertebral junction lesions (Naderi et al., 2013). This is because such cases require less extensive bony resection, both sub occipital craniotomy and occipital condylectomy. It is plausible that this knowledge may therefore be important in surgical procedures around craniocervical region within the Kenyan population. It is therefore plausible that knowledge of intercondylar distances as well as the gender differences may be important in cranio-vertebral junction surgical procedures

\section{Position of the hypoglossal canal}

Maximizing surgical field of view and minimizing brainstem retraction by extensive bone resection is a hallmark of skull base surgeries (Saeid et al., 2015). Part of this is achieved by drilling of the posterior aspect of the OC. In these procedures however, HGN palsies are not uncommon (Sen et al., 2010). This necessitates accurate knowledge of position of $\mathrm{HC}$ to avoid inadvertent injury to HGN.

In the present study, the $\mathrm{HC}$ was located at an average distance of $9.62 \pm 1.62 \mathrm{~mm}$ from the posterior tip of the OC. This is larger than that obtained by Wen et al., (1997) among the Americans. It was however smaller compared to those obtained among the Indian (Muthukumar et al., 2005), Brazilian (Pereira et al., 2012) and Iranian (Saeid et al., 2015) populations (Table 10). Muthukumar et al (2005) obtained a distance of $12.2 \mathrm{~mm}$ and stated that the maximum amount of OC that could be resected without injuring the HGN was $12 \mathrm{~mm}$. Since our sample population had smaller amount of bone that can be drilled before reaching the $\mathrm{HC}$, it plausible that they could be more prone to HGN injury should same amount of bone be removed from as in other populations. This may therefore be taken into account to minimize cases of postoperative HGN palsies.

Of note, females also had significantly shorter $\mathrm{OC}-\mathrm{HC}$ distance compared to males ( $\mathrm{p}$ value $=$ 0.008 ). To the best of our knowledge, there is paucity of literature detailing gender difference in $\mathrm{HC}$ position. Although there is paucity of literature detailing sex composition of patients with post-operative HGN palsies, it is plausible that females have higher predisposition to HGN palsies compared to males based on smaller posterior tip of OC to HC distance. Sex should therefore be taken into consideration during partial condylectomies.

In conclusion, our study population generally have smaller OC dimensions compared to other populations. Females had significantly smaller $\mathrm{OCL}, \mathrm{OCH}, \mathrm{OC}-\mathrm{HC}$ distance and PID. Clinicians should therefore take this information into consideration during preoperative planning in cranio-vertebral junction surgeries among Kenyans and particularly in females. 


\section{REFERENCES}

1. Akinbami BO. 2014. Measurement of cephalic indices in older children and adolescents of a Nigerian population. Biomedical Research International, 2014:1-5

2. Banerji D. 1999. Extreme lateral transcondylar approach to the skull base. Neurology India, 47:2230.

3. Bayat $P$, Bagheri $M$, Ghanbari A, Raoofi A. 2014. Characterization of occipital condyle and comparison of its dimensions with head and foramen magnum circumferences in dry skulls of Iran. International Journal of Morphology, 32:444-448.

4. Bello SS, Zagga AD, Kalale SB, Usman JD, Bello A, Abdulhameed A. 2013. Measurements of occipital condyles using computerised tomography from Sokoto State, Nigeria. Int J Health Med Inf.2:10-7.

5. Caird MS, Wills BPD, Dormans JP, 2006. Down syndrome in children: the role of the orthopaedic surgeon. Journal of American Academy of Orthopedic Surgery, 14:610-619.

6. Callewaert F, Sinnesael M, Gielen E, Boonen S, Vanderschueren D. 2010. Skeletal sexual dimorphism: relative contribution of sex steroids, GH-IGF1, and mechanical loading. Journal of Endocrinology, 207:127-134.

7. Fetouh F, Awadalla A. 2009. Morphometric analysis of the occipital condyle and its surgical implications in the transcondylar approach. Journal of Neurological Surgery Part B: Skull Base, 19(3): A023

8. Gökce C, Cicekcibasi AE, Yilmaz MT, Kiresi D. 2014. Morphometric analysis of bone structures in major subjects' skull base live by multidetector computed tomography. International Journal of Morphology, 32:812-821.

9. Kumar A and Nagar M, 2015. Human adult occipital condyles: A morphometric analysis. Research \& Reviews: Journal of Medical and Health Sciences, 3(4);112-116.

10. Lynch JC, Temponi V, Emmerich JC, Pereira CE, Gonçalves MB. 2013. Foramen magnum meningioma: To drill or not to drill the occipital condyle? A series of 12 patients. Surgical Neurology International, 1(4):73.

11. Mahajan D. 2013. An anatomical perspective of human occipital condyles and foramen magnum with neurosurgical correlates. International Journal of Experimental and Clinical Anatomy, 6(7):29-33.

12. Muthukumar N, Swaminathan R, Venkatesh G, Bhanumathy SP. 2005. A morphometric analysis of the foramen magnum region as it relates to the transcondylar approach. Acta Neurochirurgica, 147:889-895.

13. Naderi S, Korman E, Çıtak G, Güvençer M, Arman C, Şenoğlu M, Tetik S, Arda MN. 2005. Morphometric analysis of human occipital condyle. Clinical Neurology and Neurosurgery, 107:191-199.

14. Natsis K, Piagkou M, Skotsimara G, Piagkos G, Skandalakis P. 2013. A morphometric anatomical and comparative study of the foramen magnum region in a Greek population. Surgical and Radiological Anatomy, 35:925-934.

15. Oliviera OF de, Tinoco RLR, Daruge Júnior E, Araujo LG, de Silva RHA, da Paranhos LR. 2013. Sex determination from occipital condylar measurements by baudoin Index in forensic purposes. International Journal of Morphology, 31:1297-1300.

16. Pereira GAM, Lopes PTC, Santos AMPV, Duarte RD, Piva L, and Pozzobon A. 2012. A morphometric analysis related to the transcondylar approach in dry skulls and computed tomography. International Journal of Morphology, 30(2):399-404.

17. Saeid B, Parvindokht B, Rez D. 2015. Morphometric analysis of hypoglossal canal of the occipital bone in Iranian dry skulls. Journal of Craniovertebral Junction and Spine, 6:111.

18. Sahoo S, Giri SK, Panda SK, Panda P, Sahu MC, Mohapatra C. 2015. Morphometric analysis of the foramen magnum and the Occipital condyles. International Journal of Pharmaceutical Sciences Review and Research, 33:198-204. 
19. Sen C, Shrivastava R, Anwar S, Triana A. 2010. Lateral transcondylar approach for tumors at the anterior aspect of the craniovertebral junction. Neurosurgery, 66:104-112.

20. Sherwood RJ, Duren DL, Mahaney MC, Blangero J, Dyer TD. 2011. A genome-wide linkage scan for quantitative trait loci influencing the craniofacial complex in humans (Homo sapiens sapiens). Anatomical Record, 294:664-675.

21. Sinnatamby CS. 2006. Last's anatomy. Regional and Applied. Edinburgh, Churchill Livingstone, $12^{\text {th }}$ Edition, Page 419.

22. Smith HF. 2011. The role of genetic drift in shaping modern human cranial evolution: a test using microevolutionary modeling. International Journal of Evolutionary Biology, 21:36-47.

23. Suhardja A, Agur AMR, Cusimano MD. 2003. Anatomical basis of approaches to foramen magnum and lower clival meningioma: comparison of retrosigmoid and transcondylar approaches. Neurosurgery Focus, 14, e9.

24. Susan Standring. 2008. Gray's Anatomy, 40th Edition. Anatomical basis of clinical practice, Churchill Livingstone, London. 40:415.

25. Tange $Y$, Uto A, Wachi A, Koike J. 2001. Transcondylar fossa approach to treat ventral foramen magnum meningioma--case report. Neurologia medico-chirurgica (Tokyo), 41:458-462.

26. Vishteh AG, Crawford, NR, Melto MS, Spetzler RF, Sonntag VK, Dickman CA. 1999. Stability of the craniovertebral junction after unilateral occipital condyle resection: a biomechanical study. Journal of Neurosurgery, 90:91-98.

27. Vishteh AG, Crawford NR, Melton S, Ferguson KL, Geldmacher TR, Dickman CA, Sonntag VKH, Spetzler RF. 1998a. Stability of the craniovertebral junction after unilateral occipital condyle resection: A biomechanical study: Neurosurgery, 43:675.

28. Wen HT, Rhoton AL, Katsuta T, de Oliveira E. 1997. Microsurgical anatomy of the transcondylar, supracondylar, and paracondylar extensions of the far-lateral approach. Journal of Neurosurgery, 87:555-585.

29. Vanderschueren D, Vandenput L, Boonen S, Lindberg MK, Bouillon R, Ohlsson C. 2004. Androgens and bone. Endocrinology Review, 25:389-425. 